Vol. 2 No. 2 Juli 2019

ISSN 2614-2775

e-ISSN 2621-8143
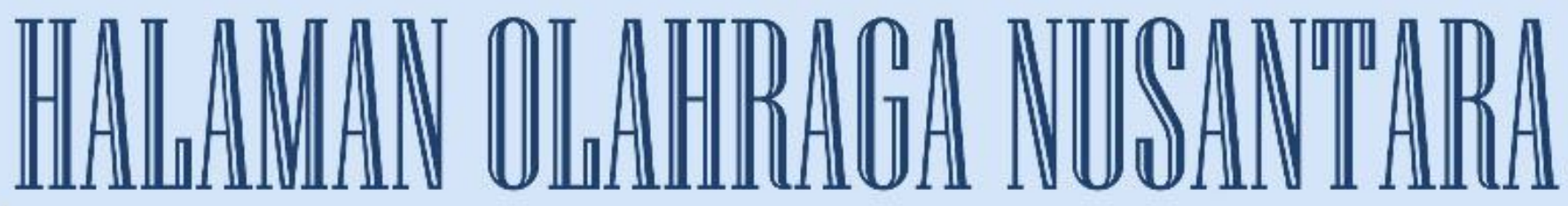

Surnal @lmu Xeolahragaan

Diterbitkan Oleh:

Program Studi Pendidikan Olahraga

Fakultas Keguruan dan Ilmu Pendidikan

Universitas PGRI Palembang

\begin{tabular}{|c|c|c|c|c|c|}
\hline Jurnal & Volume & Nomor & Halaman & Palembang & ISSN/e-ISSN \\
\hline IIalaman Oahrayg Ninsantarata & 2 & 2 & $97-197$ & 2019 & $\begin{array}{c}2614-2775 / \\
2621-8143\end{array}$ \\
\hline
\end{tabular}


Halaman Olahraga Nusantara (Jurnal Ilmu Keolahragaan)

P-ISSN 2614-2775

Volume 2, No. 2, Januari 2019

E-ISSN 2621-8143

\section{DAFTAR ISI}

Hasil Penelitian

Halaman

Penerapan Model Permainan Rounders Yang Dimodifikasi Terhadap Kemampuan Gerak Dasar Murid Sd Negeri Paccinongan Kabupaten Gowa

- Benny B, M.Rachmat Kasmad

Pelaksanaan Kegiatan Belajar Mengajar Pendidikan Jasmani di Sekolah Dasar Inklusi

- Bambang Gatot Sugiarto

Pengaruh Metode Latihan Terhadap Daya Tahan Fisik Siswa Ekstrakurikuler Sepak Bola Sma N 2 Tanjung Raja

- Mutiara Fajar.

Survei Minat Member Yang Mengikuti Fitness Pada Pusat Kebugaran Kota Palembang

- Hengki Kumbara.

Peningkatan Pengaruh Latihan Kelincahan Terhadap Kemampuan Menggiring Bola Pada Siswa Sma Negeri 3 Samarinda

- Ruslan, Nurjamal

Penerapan Permainan Dengnan Media Swiss Ball Untuk Meningkatkan Kelentukan Lower Back (Pada Mahasiswa Kop Aerobic Gymnastics Universitas Negeri Jakarta)

- M Dian Susanto, Sri Nuraini $141-153$

Patrol Multiguna Sebagai Alternatif Media Pembelajaran Tolak Peluru Di Smp Negeri 1 Sei Balai Kabupaten Batu Bara Tahun Ajaran 2017/2018

- Joko Priono $154-166$ 
Kecerdasan Gerak Dalam Pendidikan Jasmani

- Hilda Oktriyeni....................................................................... 167-176

Analisis Kesalahan Tendangan Atlet Pencak Silat Universitas PGRI Palembang

- Bayu Iswana............................................................................ 177-185

Pengaruh Metode Pembelajaran Dan Kriteria Layanan Bantuan:

Meningkatkan Gerak Dasar Lompat Jauh Gaya Jongkok Siswa Tunagrahita Ringan Pada Pembelajaran Penjasorkes SLB PKK Bandar Lampung

- Rachmi Marsheilla Aguss.............................................................. 186-197 


\title{
PENGARUH METODE LATIHAN TERHADAP DAYA TAHAN FISIK SISWA EKSTRAKURIKULER SEPAK BOLA SMA N 2 TANJUNG RAJA
}

\author{
Oleh :Mutiara Fajar, M.Pd \\ (Dosen Universitas PGRI Palembang)
}

\begin{abstract}
Abstrak
Masalah dalam penelitian ini adalah siswa ekstrakurikuler SMA N 2 Tanjung Raja masih sering mengalami kelelahan fisik saat bertanding sepak bola, Penelitian ini merupakan penelitian eksperimen. Tujuan Penelitian in untuk melihat perbedaan hasil latihan interval dan fartlek terhadap daya tahan fisik siswa ekstrakurikuler sepakbola SMA Negeri 2 Tanjung Raja. Sampel yang diambil seluruh siswa ekstrakurikuler sepak bola SMA Negeri 2 Tanjung Raja didasakan apabila subyek yang diteliti jumlahnya kurang dari 100 maka akan lebih baik diambil semua sebagai sampel, jadi teknik yang dilakukan dalam pemilihan sampel penelitian adalah total sampling dengan jumlah 20 siswa. Berdasarkan analisa data Adanya pengaruh metode latihan interval dan latihan fartlek terhadap daya tahan fisik siswa ekstrakurikuler SMA Negeri 2 Tanjung Raja. Terdapat perbedaan latihan interval dan latihan fatrlek terhadap daya tahan fisik siswa ekstrakurikuler sepak bola SMA Negeri 2 Tanjung Raja karena $t$ hitung $>t_{\text {tabel }}(1,79>1,72)$. Berdasarkan data di atas, diperoleh keterangan bahwa latihan interval memberikan kontribusi peningkatan sebesar $28,5 \%$ terhadap daya tahan fisik siswa, dan latihan fartlek memberikan kontribusi sebesar 52,25\% dengan tingkat perbedaan signifikan. Hal tersebut dapat disimpulkan bahwa dari kedua kelompok latihan artinya latihan fartlek memberikan kontribusi lebih besar jika di bandingkan kelompok latihan interval.
\end{abstract}

Kata Kunci : Latihan Interval, Latihan Fartlek, Daya tahan fisik

\section{THE EFFECT OF EXERCISE STUDY ON PHYSICAL RESISTANCE OF FOOTBALL EXTRACURRICULAR STUDENTS IN TANJUNG RAJA 2 STATE HIGH SCHOOL}

\begin{abstract}
The problem in this study is that extracurricular students at Tanjung Raja High School $2 \mathrm{~N}$ are still often experiencing physical fatigue when competing in soccer, this research is an experimental study. The purpose of this study was to see the differences in the results of interval and fartlek training on the physical endurance of students at Tanjung Raja 2 High School extracurricular football. Samples taken by all Tanjung Raja 2 Senior High School soccer extracurricular students were obtained if the subjects studied were less than 100 so it would be better to take all as samples, so the technique used in selecting research samples was total sampling with a total of 20 students. Based on data analysis There is an influence of interval training methods and fartlek training on the physical endurance of extracurricular students at Tanjung Raja 2 Public High School. There are differences in interval training and fatplate training on the physical endurance of students of Tanjung Raja SMA 2 extracurricular football
\end{abstract}


because t count $>$ t table (1.79> 1.72). Based on the data above, it was obtained information that interval training contributed a $28.5 \%$ increase in students' physical endurance, and fartlek training contributed $52.25 \%$ with a significant degree of difference. It can be concluded that from the two groups of exercises it means that fartlek training contributes more if compared to the interval training group.

Keywords: Interval Exercises, Fartlek Exercises, Physical Endurance

\section{A. PENDAHULUAN}

Olahraga adalah serangkaian kegiatan dalam bentuk permainan yang mengedepankan aspek kompetisi terstruktur dengan beragam aturan yang ada di dalamnya. Olahraga memiliki nilai-nilai yang dapat dijadikan tolak ukur perkembangan mahluk hidup. Diantaranya adalah aspek kognitif, apektif dan psikomotorik. Perkembangan olahraga dewasa ini semakin menunjukan kemajuan. Terbukti olahraga di berbagai Negara bahwa olahraga telah memasuki ranah pendidikan. Dalam Undang-Undang Sistem Keolahragaan Nasional (SKN) tahun 2005 (2011:5) menjelaskan pada pasal 6 bahwa olahraga berdasarkan tujuan telah dibedakan menjadi tiga bagian diantaranya adalah olahraga kompetisi, rekreasi dan pendidikan. Dalam dunia pendidikan, olahraga masuk ke ranah pendidikan jasmani. Ada banyak cabang olahraga yang dikenalkan melalui pendidikan jasmani dan bahkan beberapa sekolah telah melakukan pembinaan melalui wadah ekstrakurikuler, salah satunya adalah sepak bola.

Berbicara sepak bola maka sudah tentu olahraga ini merupakan olahraga tim yang membutuhkan kekompakkan dan kesolidan antar pemain. Tim yang benar-benar kompak dan solid serta didukung oleh strategi yang jitu sudah dipastikan akan memenangkan pertandingan dan dapat memuaskan hati penonton sebagai penggemarnya. Strategi yang dimaksudkan di atas memiliki makna yang sangat komplek, alasannya strategi dibutuhkan tidak hanya kekompakkan dan kesoliddan tim melainkan lebih dari pada itu semua unsur penunjang terhadap munculnya prestasi sepak bola harus di atur dan dimanajemen dengan baik, khususnya kualitas fisik pemain tersebut.

Sepak bola merupakan permainan yang dimainkan dalam kurun waktu $2 \mathrm{x}$ 45 menit waktu normal. 2 x 45 menit waktu normal setiap pemain harus berlari 
dan berjuang untuk memenangkan pertandingan. Fisik yang prima sudah tentu sangat menjadi andalan untuk memenangkan pertandingan. Tetapi fisik yang lemah sudah tentu menyebabkan permainan akan sangat sulit untuk dijalankan dengan baik, strategi taktik yang jitu tidak tetapi kualitas fisik yang lemah akan menyebabkan kegagalan. Respon fisiologis seperti ini biasanya sangat dibutuhkan karena otak akan merangsang kemampuan taktik jika fisik bekerja maksimal. Pentingnya kualitas fisik pemain sepak bola membuat setiap pelatih harus selalu memutar otak agar selalu dapat meningkatkan daya tahan fisik setiap pemainnya. Latihan demi latihan harus terus dijalankan agar kondisi fisik pemain dapat selalu meningkat. Maka setiap pelatih harus memiliki metode latihan yang tepat dalam memberikan menu latihan. Latihan yang dimungkinan dapat meningkatkan daya tahan fisik seperti interval training dan fartlek.

Sukadiyanto (2012: 67) mengatakan bahwa berdasarkan jenisnya latihan interval adalah jenis latihan yang sangat penting dalam jadwal latihan modern. Interval mengedepankan faktor-faktor di antaranya adalah jarak lari, jumlah ulangan lari, tempo atau kecepatan lari, interval atau waktu istirahat. Sedangkan latihan fartlek adalah bentuk aktivitas lari yang dilakukan dengan cara jalan, jogging, sprint, dan jalan secara terus menerus. Melihat dari jenis latihanya, hal ini sangat sejalan dengan konsep permainan sepak bola yang kadang kala membuat pemain sepak bola harus berlari dengan sangat cepat, kadang-kadang istrihat dengan jalan biasa dan kadang-kadang harus berlari jauh. Dengan konsep latihan interval tersebut maka ada kemungkinan daya tahan fisik siswa dapat ditingkatkan. Gambaran kualitas fisik yang dimiliki pemain sepak bola pada setiap tim memiliki tingkat yang berbeda-beda. Ada yang baik, ada yang baik sekali, ada yang tidak sama sekali. Kondisi fisik yang tidak sama sekali, biasanya cenderung di level club-club amatir misalnya club club binaan sekolah seperti ekstrakurikuler sepak bola.

Berdasarkan observasi peneliti pada salah satu ekstrakurikuler sepak bola yaitu sekolah SMA Negeri 2 Tanjung Raja maka temuan kebugaran atau kondisi fisik pada ekstrakurikuler sekolah ini masih sangat jauh dari harapan. Hal tersebut terbukti dengan pertandingan baru berjalan kurang dari 30 menit siswa sudah 
mengalami kelelahan dan meminta untuk diganti. Berdasarkan data empiris yang diminta peneliti pada pelatih ekstrakurikuler sepak bola SMA Negeri 2 Tanjung Raja, ditemukan bahwa rata-rata VO2Maks siswa masih di bawah 35 artinya kondisi tersebut dikategorikan kurang. Hal tersebut menjadi kendala dalam bermain sepak bola, oleh karenanya untuk meningkatkan kemampuan VO2maks tersebut dibutuhkan menu latihan yang tepat.

Dari uraian permasalahan di atas, peneliti bermaksud untuk melakukan studi eksperimen bahwa kualitas daya tahan fisik pemain ekstrakurikuler sepak bola SMA Negeri 2 Tanjung Raja harus dibentuk melalui metode latihan yang tepat. Adapun judul penelitian yang akan dilaksanakan adalah "Pengaruh metode latihan terhadap daya tahan fisik siswa ekstrakurikuler sepak bola SMA Negeri 2 Tanjung Raja”.

\section{B. METODE PENELITIAN}

Penelitian ini menggunakan metode penelitian eksperimen lapangan. Metode eksperimen merupakan metode yang paling tepat untuk menyelidiki hubungan sebab akibat. Sesuai dengan pendapat dari Suharsimi Arikunto (2013 : 9), penelitian eksperimen adalah suatu cara untuk mencari hubungan sebab akibat antara dua faktor yang sengaja ditimbulkan oleh peneliti dengan mengurangi atau menyisihkan faktor-faktor lain yang mengganggu.

Paradigma peneltitian yang tepat untuk jenis penelitian ini adalah (pretesttest control group disain) dapat digambarkan sebagai berikut:

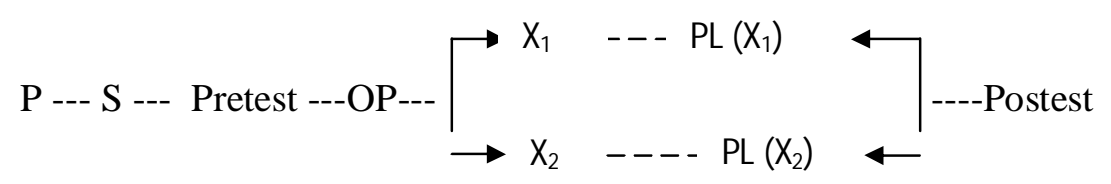

Gambar 3.1. Pretest-Posttest Control Group Design

(Sumber: Arikunto, 2010: 124)

Keterangan :

P : Populasi

S : Sampel

Pretest : Tes Awal Kemampuan 


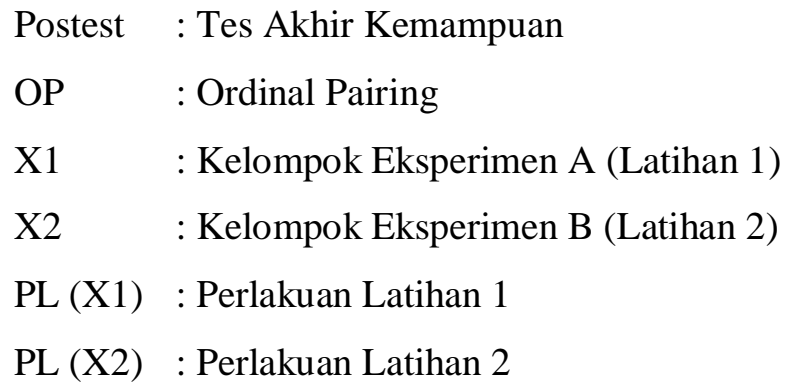

Untuk mengetahui sejauh mana perbedaan pengaruh latihan interval dan fartlek terhadap peningkatan daya tahan fisik. Maka data yang diperoleh dianalisis dengan menggunakan rumus statistik menggunakan teknik analisis " $t$-test".

Sebelum data diolah terlebih dahulu dilakukan uji normalitas data dan uji homogenitas data. Uji normalitas bertujuan untuk mengetahui apakah kelompok sampel berasal dari yang berdistribusi normal atau tidak. Untuk menguji normalitas tersebut dilakukan uji liliefors. Sedangkan uji homogenitas bertujuan untuk melihat apakah kedua kelompok data mempunyai variasi yang homogen atau tidak. Untuk mendapatkan hal tersebut digunakan uji variasi.

\section{HASIL DAN PEMBAHASAN}

Uji normalitas dilakukan dengan menggunakan uji lilliefors dengan taraf nyata $(\alpha)=0.05$, kriteria pengujian adalah bahwa $\mathrm{H}_{\mathrm{o}}$ ditolak apabila $\mathrm{L}_{\mathrm{o}}$ yang diperoleh dari data pengamatan melebihi $L_{t}$ dan sebaliknya $H_{o}$ diterima apabila $L_{t}$ lebih besar dari $L_{o}$ secara sederhana dapat digunakan rumus sebagai berikut:

$$
\begin{aligned}
& \mathrm{H}_{\mathrm{o}}=\text { diterima apabila } \mathrm{L}_{\mathrm{o}}>\mathrm{L}_{\mathrm{t}} \\
& \mathrm{H}_{\mathrm{a}}=\text { diterima apabila } \mathrm{L}_{\mathrm{o}}<\mathrm{L}_{\mathrm{t}}
\end{aligned}
$$

Persyaratan analisis lainnya yang diperlukan dalam penelitian ini adalah pengujian homogenitas varians. Pengujian homogenitas varians yang dilakukan dalam penelitian ini adalah : pengujian homogenitas data awal (pre test) daya tahan fisik dari dua kelompok perlakuan yaitu antara kelompok latihan interval dan latihan fartlek $\left(\mathrm{X}_{1 \text { dan }} \mathrm{X}_{2}\right)$.

Uji homogenitas ini dilakukan untuk melihat apakah data yang diperoleh berasal dari data yang homogen. Uji homogenitas varians menyatakan bahwa 
apabila $F_{\text {hitung }}\left(F_{h}\right)$ lebih kecil dari $F_{\text {tabel }}\left(F_{t}\right)\left(F_{h}<F_{t}\right)$ sesuai dengan taraf signifikan $\alpha=0,05$ maka kedua kelompok data berasal dari varians yang homogen.

Besarnya persentase peningkatan masing-masing kelompok dari nilai pretest ke postest dengan rumus:

$$
\begin{aligned}
& =\frac{\sum}{\Gamma} \quad 100=\frac{3,42}{12} \quad 100=28,5 \% \\
& =\frac{\Sigma}{100}=\frac{6,39}{12} \quad 100=52,25 \%
\end{aligned}
$$

Berdasarkan hasil perhitungan data deviasi pretest dan postest di atas, diperoleh keterangan bahwa :

a. Besarnya peningkatan kualitas latihan interval terhadap daya tahan fisik siswa adalah $28,5 \%$.

b. Besarnya peningkatan kualitas latihan fartlek terhadap daya tahan fisik siswa adalah $52,25 \%$.

Setelah data dinyatakan berdistribusi normal dan sampel berasal dari populasi yang homogen maka selajutnya dapat dilakukan pengujian hipotesis mengunakan rumus statistik "uji t" yaitu :

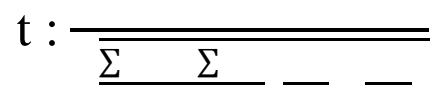

Kreteria pengujian diterima Ho jika $\mathrm{t}_{\text {hitung }}<\mathrm{t}_{\text {tabel }}$ dan tolak Ho atau terima Ha jika

$$
\begin{array}{rlrl}
\mathrm{t}_{\text {hitung }} & >\mathrm{t}_{\text {tabel. }} . \\
\sum & =3,42 \sum=6,39 & \sum=2,147 \quad \sum=6,939 \\
\mathrm{Mx} & =\underline{\Sigma}=\frac{}{}=0,285 & \mathrm{My}=\underline{\Sigma}=\underline{ }=0,524
\end{array}
$$

Selanjutnya menghitung nilai :

$$
\begin{array}{lll}
\Sigma & =\Sigma & -\frac{(\Sigma)}{2}=2,147-\frac{(, \quad)}{2}=2,147-0,974=1,173 \\
\Sigma & =\Sigma & -\frac{(\Sigma)}{2}=6,939-\frac{(, \quad)}{2}=6,939-3,402=3,536
\end{array}
$$

Setelah mendapatkan hasil Mx, My, $\Sigma$ dan $\Sigma$, maka masuk ke dalam uji t dengan perhitungan sebagai berikut :

$$
\mathrm{t}=\frac{\overline{\bar{\Sigma} \Sigma}-}{\underline{\Sigma}}
$$




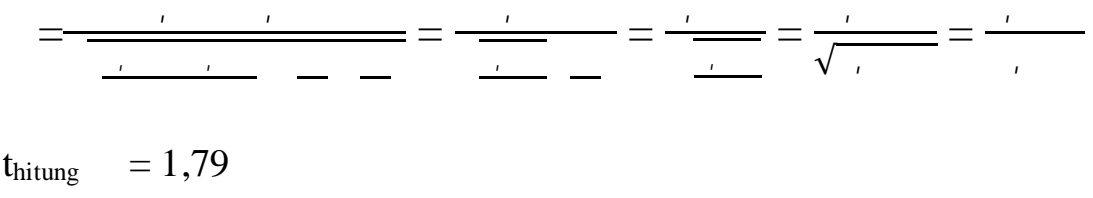

Menentukan $t_{\text {tabel }}$ dengan taraf kepercayaan $=0,05$ untuk $\mathrm{Dk}=\mathrm{n} 1+\mathrm{n} 2-$ $2=12+12-2=24-2=22$ adalah 1,717. Telah dijelaskan bahwa kreteria pengujian hipotesis terima Ho jika $\mathrm{t}_{\text {hitung }}<\mathrm{t}_{\text {tabel }}$ dan tolak Ho atau terima Ha jika $\mathrm{t}$ hitung $>t_{\text {tabel. }}$. Berdasarkan hasil uji-t diatas di peroleh $\mathrm{t}_{\text {hitung }}=1,79$ sedangkan $\mathrm{t}_{\text {tabel. }}$. $=1,717$. Jika diperhatikan bahwa $t_{\text {hitung }}>\mathrm{t}_{\text {table, }}$, artinya hipotesis diterima. Dengan demikan dapat dikatakan bahwa ada perbedaan latihan interval dan latihan fartlek terhadap daya tahan fisik siswa ekstrakurikuler sepak bola SMA Tanjung Raja.

\section{KESIMPULAN}

Berdasarkan hasil perhitungan data dan analisis penelitian, penelitian ini memberikan kesimpulan bahwa ada perbedaan yang signifikan antara latihan interval dan latihan fartlek terhadap daya tahan fisik siswa ekstrakurikuler sepak bola SMA Negeri 2 Tanjung Raja, hal ini dibuktikan dengan nilai $t_{\text {hitung }}>t$ tabel $(1,79>1,717)$.

\section{DAFTAR PUSTAKA}

Arikunto, Suharsimi. 2010. Prosedur Penelitian Suatu Pendekatan Praktik. Jakarta: Rineka Cipta.

Busyairi, B. Ray, HRD. 2018. Perbandingan Metode Interval dan Contiunuos Run. Unversitas Pendidikan Indonesia.

Dery, LA. 2014. Pengaruh Latihan Fartlek. Universitas Bengkulu.

Hidayat. 2014. Pengaruh Interval Training Terhadap Kecepatan Atlet Sepak Bola. Universitas Negeri Jakarta.

Ismaryati. 2010. Tes dan Pengukuran Olahraga. Semarang : Universitas Sebelas Maret.

Kurniawan, DM, Pujdianto, M. 2017. Perbedaan Interval Training, Sirkuit Training Terhadap Terhadap Daya Tahan. Universitas Muhammadiyah Surakarta. 
Luxbacher. 2004. Latihan Sepak Bola. Alfabeta; Bandung.

Maliki, O. Hadi, H. Royana FI. 2017. Analisis Kondisi Fisik Pemain Sepak Bola. Universitas PGRI Semarang.

Mileke. Danny. 2007. Sepak Bola. Alfabeta; Bandung.

Nasution, A. 2018. Survey Teknik Dasar Permainan Sepak Bola.Universitas Negeri Makasar.

Nurhasan. 2001. Tes Dan Pengukuran Dalam Pendidikan Jasmani PrinsipPrinsip Dan Penerapannya. Jakarta: Direktorat Jenderal Olahraga, Depdiknas.

Sugiyono. 2010. Statistika Untuk Penelitian. Bandung : CV Alfabeta.

Sukadiyanto. 2011. Pengantar Teori Dan Metodelogi Melatih Fisik. Yogyakarta: FIK UNY.

Sukirno. 2012. Kesehatan Olahraga, Kesegaran Jasmani dan Doping. Unsri Perss.

Widiastuti. 2011. Tes dan Pengukuran. Alfabeta; Bandung.

Wihoho, HA. Junaidi, S. Sugiarto. 2014. Profil Kondisi Fisik Siswa Ekstrakurikuler. Universitas Negeri Semarang. 